\title{
Evidence based prevention of acute injuries during physical exercise in a WHO safe community
}

T Timpka, K Lindqvist

\begin{abstract}
Objective-To evaluate a community based programme for evidence based prevention of injuries during physical exercise. Design-Quasi-experimental evaluation using an intervention population and a non-random control population.

Participants-Study municipality (population 41000 ) and control municipality (population 26 000) in Sweden.

Main outcome measures-Morbidity rate for sports related injuries treated in the health care system; severity classification according to the abbreviated injury scale (AIS).

Results-The total morbidity rate for sports related injuries in the study area decreased by $14 \%$ from 21 to 18 injuries per 1000 population years (odds ratio 0.87 ; $95 \%$ confidence interval (CI) 0.79 to 0.96 ). No tendency towards a decrease was observed in people over 40. The rate of moderately severe injury (AIS 2) decreased to almost half (odds ratio 0.58 ; $95 \%$ CI 0.50 to 0.68 ), whereas the rate of minor injuries (AIS 1) increased (odds ratio $1.22 ; 95 \%$ CI 1.06 to 1.40 ). The risk of severe injuries (AIS 3-6) remained constant. The rate of total sports injury in the control area did not change (odds ratio $0.93 ; 95 \%$ CI 0.81 to 1.07 ), and the trends in the study and control areas were not statistically significantly different.

Conclusion-An evidence based prevention programme based on local safety rules and educational programmes can reduce the burden of injuries related to physical exercise in a community. Future studies need to look at adjusting the programme to benefit all age groups. (Br F Sports Med 2001;35:20-27)
\end{abstract}

Keywords: injuries; prevention; evaluation; community; intervention; safety promotion

Only a few decades ago, sport and physical exercise were usually omitted from the public health agenda. ${ }^{1}$ Today, as a result of the spread of a sedentary lifestyle, the situation has changed. Morbidity from cardiovascular disease has been confirmed to be inversely related to the level of leisure time physical activity. ${ }^{23}$ Recent studies have suggested that the inverse relation between exercise and disease also holds for other organ systems, ${ }^{4}$ and that this relation persists after adjustment for familial factors. ${ }^{5}$ An example of causal mechanisms is the positive effect of exercise on bone density at the hip in postmenopausual women. ${ }^{6}$ There is plenty of evidence from a public health perspective to encourage physical activity among the young and to promote maintenance of exercise with increasing age. However, in parallel with the benefits, there is the risk of injury. ${ }^{7}$ Community based studies in Scandinavia have suggested that every sixth unintentional injury is associated with leisure time physical exercise ${ }^{89}$ Factors known to influence the risk of injury are the nature of the exercise (vigorousness, rules), the equipment and the environment (clothes and footwear, facilities, weather conditions), and individual characteristics (age, experience, technique).$^{10}$

Comprehensive programmes for prevention of injuries related to physical exercise have been called for. ${ }^{11}$ One strategy for injury prevention is to collect and analyse local injury data and then supply the results to local organisations with an interest in decreasing injury rates in the community. The first community development programme aimed at preventing injuries was initiated in 1978 in the municipality of Falköping, Sweden. ${ }^{12}$ The aim of the present study is to evaluate the effect of using such a model, the WHO safe community programme, on sports related injuries. Sport is defined as a leisure time physical activity requiring vigorous bodily exertion and carried out according to a traditional form or set of rules. Using a quasi-experimental design, the specific aim is to analyse changes in community level morbidity rate, taking into account injury severity and anatomical location. Only injuries requiring medical attention are included in the evaluation.

The evaluated WHO safe community programme is implemented in Motala municipality in the western part of Östergötland County in Sweden. An assessment of the general structure and process of the programme has previously been reported. ${ }^{13}$ In the community analysis stage, performed in 1983/1984, the local epidemiology of injuries during physical exercise was studied, and the local social structure and values were analysed. ${ }^{914}$ An interorganisational sports safety council was formed with representatives from the municipality's leisure time administration, the Educational Association of the Swedish Sporting Organisations (SISU), the 
Intercompany Sports Association, the health care administration, schools, and the local alliance of soccer clubs. Injuries sustained during team sports were found to predominate, soccer accounting for $39 \%$ of the injuries, followed by handball/basketball $(10 \%)$. About $60 \%$ of the soccer injuries were consequences of aggressive play-that is, tackles, kicks, and blows. It was also found that intercompany team competitions took place with few practice sessions before matches, no time allotted for warming up, and few coaches and trained instructors. Stage two, the programme design and initiation (1985-1987) stage, included organising management of the interventions and setting local planning goals. Injuries incurred during physical exercise, more than injuries in other environments, were seen to be related to a person's conscious choice of leisure time activity. As a person's decision to use leisure time for physical exercise was seen as essential for community health, the interventions had to restrict minimally the choice of physical exercise as a leisure time activity. The implementation stage (1987-1988) included population based interventions at three levels.

- Community level: all physical education teachers in the study area participated in an injury prevention course organised by SISU; high risk groups were investigated.

- Sports organisation level: SISU was given the primary responsibility for coordinating interventions. In team sports, the emphasis was put on safety norms and rules. On the basis of experience from ice hockey ${ }^{16}$ workshops for coaches and referees were used to define a fair play programme to discourage foul play. In addition, the administrators of the Intercompany Sports Association introduced compulsory use of shin pads during intercompany soccer matches as well as warming up programmes before kick off. For individual sports, a specific attempt was made to increase supervision of novices. For instance, a rule was introduced prescribing supervision of young riders during all interaction with horses.

- Group level: the alliance of soccer clubs arranged courses for local coaches on how injuries can be avoided by proper physical preparation. ${ }^{17}$

Individual interventions were mediated through the introduction of a sports medicine service in the primary care system. During the intervention year, 120 patients were examined by a specially trained doctor or physiotherapist. Based on the findings, individual advice was given on rehabilitation and how to avoid injury in the future. At stage four, programme maintenance-consolidation (1989-1995), the intervention activities were further integrated into existing community networks. The final stage, evaluation (1995-1999), focused on assessing and reporting results from the programme.

\section{Methods}

A quasi-experimental design ${ }^{18}$ was used, with measurements taken before and after implementation in the programme implementation area and in a neighbouring control municipality in Östergötland county. The main intervention effect was studied using prospective registration of all acute health care episodes during the study period. As the study areas were not randomly chosen, environmental indicators were studied. To avoid bias, the research team was composed of evaluators who had not taken part in the implementation and programme managers with experience of the programme process.

\section{DEFINITIONS}

The ICD- 8 was used to classify the nature and external cause of the injury. ${ }^{19}$

A sport related injury was defined as an injury requiring treatment in the health care system sustained during a leisure time physical activity that required more or less vigorous bodily exertion and carried out according to a traditional form or set of rules. Sport related injuries occurring at school were included. The abbreviated injury scale (AIS-80) ${ }^{20}$ was used to classify the severity of the injury into three levels: AIS 1, minor; AIS 2, moderate; AIS 3-6, severe-fatal. ${ }^{21}$

\section{DATA COLLECTION}

The study period before implementation covered the 52 weeks from 1 October 1983 to 30 September 1984. The period after implementation covered the 52 weeks from 1 January 1989 to 31 December 1989.

Data were collected for all patients presenting at a health care unit located in the study and control areas during the registration periods. A report form with the time of contact and standard personal data was filled in by staff at the care unit. On the same form was recorded whether unintentional injury was a possible reason for the visit.

Two specially trained nurses made an injury classification from the medical records after the care episode. Injury severity was only recorded in the study area. When necessary, the attending doctor was asked to help to classify the injury. The registration model was based on experiences from earlier prevention programmes in Sweden. ${ }^{22}$

The routine for data collection was tested in a pilot project. Before the start of each study period, the staff at the relevant health care units were carefully instructed, and the routine was practised over two weeks.

\section{VALIDITY AND RELIABILITY TESTS}

To identify confounding social trends, population variables possibly related to the sports injury rate were selected with the guidance of social change theory. ${ }^{23}{ }^{24}$ Data on population age and sex mix, sites of residency, education, income, and employment were collected retrospectively from national registers (Statistics Sweden) for the study periods. Whereas physical exercise is often performed as a scheduled activity among adults, children practice their favourite sports both in improvised play and by participation in organised training and competition. In the light of previous experience, ${ }^{25}$ no registration of risk exposure among participants was performed. Instead, membership 
and activity data from local sports clubs in the study area were followed.

The study area had four health care centres and a county annex hospital with a casualty department, whereas the control area shared the annex hospital and had two health care centres, one of which had an emergency unit. The use of acute health care services at these units was followed by recording data from all attendances during both registration periods. Both the study and control areas are situated $50 \mathrm{~km}$ from Linköping University Hospital. Systematic differences between the areas with regard to injured people attending for care outside the registration areas were sought by analysing all attendances at the emergency departments of the university hospital during September 1984. Fatal injuries other than those recorded in the study were researched by analysing local police records.

To estimate the quality of the specific injury registration procedure, secondary sampling of all acute health care attendances in the study area was undertaken during the third week of the registration period before implementation and in both the study and control areas during the third week of the registration period after implementation.

\section{STATISTICAL ANALYSIS}

Statistical analyses were based on the cumulative rate of sports injuries in the community. Changes in the relative risk of injury associated with the factor "exposure to the safe community programme" were estimated by odds ratio. ${ }^{26}$

\section{Results}

ENVIRONMENTAL INDICATORS

Age and sex mix in both areas were close to the national average. Residential and income characteristics also remained stable (table 1 ). The educational level in both areas was slightly below the national average and showed a tendency to increase. The proportion of the population in the study area who were members of a sports club was $39 \%$ in both $1983 / 1984$ and 1989 , whereas their activity level increased by $12 \%$, from 730000 participations in organised sport in $1983 / 1984$ to 820000 participations in 1989.

\section{QUALITY OF REGISTRATIONS}

During the registration period before implementation, which also included injuries other than sports injuries, identity data were missing for 18 of the 4926 injured patients $(0.4 \%)$ in the study area and $23(0.9 \%)$ of the 2694 injured patients in the control area. During the

Table 1 Sociodemographic trends in the study area (Motala) and control area (Mjölby) over the registration periods

\begin{tabular}{|c|c|c|c|c|}
\hline & \multicolumn{4}{|c|}{ Population characteristics (\%) } \\
\hline & \multicolumn{2}{|l|}{ Study area } & \multicolumn{2}{|l|}{ Control area } \\
\hline & $\begin{array}{l}1984 \\
(n=41400)\end{array}$ & $\begin{array}{l}1989(n=41 \\
700)\end{array}$ & $\begin{array}{l}1984 \\
(n=25900)\end{array}$ & $\begin{array}{l}1989 \\
(n=26100)\end{array}$ \\
\hline Urban residents & 82 & 82 & 79 & 81 \\
\hline Gainfully employed & 49 & 50 & 49 & 51 \\
\hline Average income ${ }^{\star}$ & 93 & 93 & 93 & 93 \\
\hline
\end{tabular}

^Percentage of national mean. period after implementation, which also includes non-sport related injuries, 10 of the 4287 injured patients $(0.2 \%)$ in the study area could not be identified in the medical records. For six of the 2746 injured patients $(0.2 \%)$ in the control area, identity data were missing.

In the registration control during the period before implementation, five (5\%) of the 102 secondarily observed injuries were found not to have been registered in the study area: three had mistakenly not been registered as injuries and two others were found not to have been recorded. During the period after implementation in the study area, four (5\%) of 84 secondarily observed injuries had not been registered; these had not been recorded. In the control area, seven (14\%) of 51 secondarily observed injuries had not been registered: three had mistakenly not been registered as injuries and four others had not been recorded.

A lower proportion of all injured residents from the study area $(11 / 422 ; 3 \%)$ than from the control area $(28 / 253 ; 12 \%)$ was found to have been directly provided with acute care at the university hospital during the month of the control study.

\section{INJURY RATES}

In the study area, the total rate of sports related injuries decreased by $14 \%$ (table 2 ), corresponding to a change from 21 to 18 injuries per 1000 population years. No tendency to decrease was observed in people over 40 . In the control area, there was no evident change in total morbidity, although a tendency towards a decrease was observed (from 16 to 15 injuries per 1000 population years). The trends in the study and control areas were not statistically significantly different. Taking injury severity into account, the risk of moderately severe injury in the study area was reduced to almost half (odds ratio $0.58 ; 95 \%$ confidence interval (CI) 0.50 to 0.68 ), while the minor injuries increased (odds ratio $1.22 ; 95 \%$ CI 1.06 to 1.40). At the same time, the risk of severe or fatal injuries remained constant.

\section{TYPE OF SPORT}

In the study area, total rates decreased only for injuries sustained in the two dominant team sports (table 3). In both of these, soccer (odds ratio $0.72 ; 95 \%$ CI 0.46 to 1.14 ) and handball/ basketball (odds ratio $0.61 ; 95 \%$ CI 0.36 to 1.06), injuries to the upper extremities showed the strongest tendency to decrease. For moderate injuries, the rates were reduced by more than one third for the dominant team sports, soccer, handball/basketball, and ice hockey, and for horse riding and skiing among the individual sports. For all sports, the rates for severe or fatal injuries remained constant.

\section{ANATOMICAL LOCATION}

In the study area, the total rate decreased for injuries to the upper extremities and the trunk (table 4). The decrease was most pronounced for upper extremity injuries sustained during horse riding, which were reduced to one quarter (odds ratio $0.21 ; 95 \%$ CI 0.06 to 0.74 ). For 


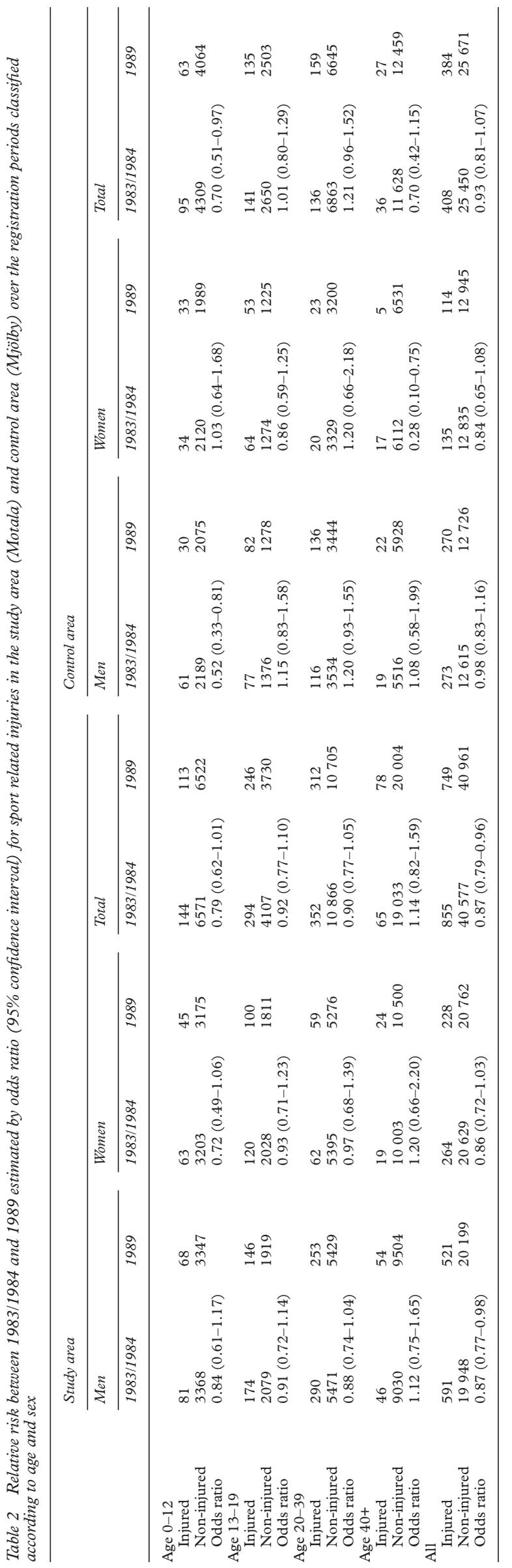

moderate injuries, the morbidity rates were reduced by half or more for injury to the upper extremities and for multiple site injury. For all anatomical locations, the risk of severe or fatal injuries remained constant.

\section{Discussion}

Because of its very nature, physical exercise always has the risk of unintentional injuries. Large scale promotion of physical exercise in a community for public health reasons ${ }^{28}{ }^{29}$ should therefore be accompanied by a programme for control and prevention of injuries. It has been concluded that in the action logic for injury prevention, the occurrence and severity of injuries in different strata of the population have to be considered. ${ }^{30}$ In this study, a programme based on this view was evaluated. The total rate for sports related injuries decreased in the study population, and the risk for injury other than minor was reduced to almost half. The decrease in total morbidity rate was still not statistically significantly different from that of the control population, which suggests a global declining trend in injury rates. The difference between total outcome and outcome with regard to nonminor injuries can be explained by the programme aim: to prevent injuries while minimally discouraging leisure time physical activity in the population.

A disappointing result is that no decrease in injury risk was observed among people over 40 . One reason may be that people in these age groups participate less in traditional sports. Instead, they choose lifestyle types of physical exercise, such as cycling to work or gardening, which were not touched by the programme. Injuries sustained during lifestyle physical activities were not included because their prevention would require measures other than those involving local sports organisations. A further deficiency in the study was that no differentiation was made between subjects below and above retirement age. The programme design needs to be modified to include analysis of physical exercise preferred by these subgroups and the participation of senior citizen organisations in the design of interventions. Specific measures can then be implementedfor example, for prevention of repeated falls during daily exercise among the old.

Another apparently disappointing result is that no decrease in the most severe injuries was observed. However, because of the low baseline rate of injuries in this category, a conclusive statistical analysis was not possible using the present data set. The cause of severe sports related injuries has been described as an interplay between exceptionally unfavourable and unusual conditions. ${ }^{31}$ Therefore, as a rule, severe injuries are not prevented by interventions directed towards injuries that are epidemiologically the most common. Consequently further studies of severe sports related injuries at community level are needed. One way to identify common causative factors is detailed analysis of fatal accidents. ${ }^{32}$

The study design does not permit us to infer any association between specific interventions and programme outcomes. However, there are 


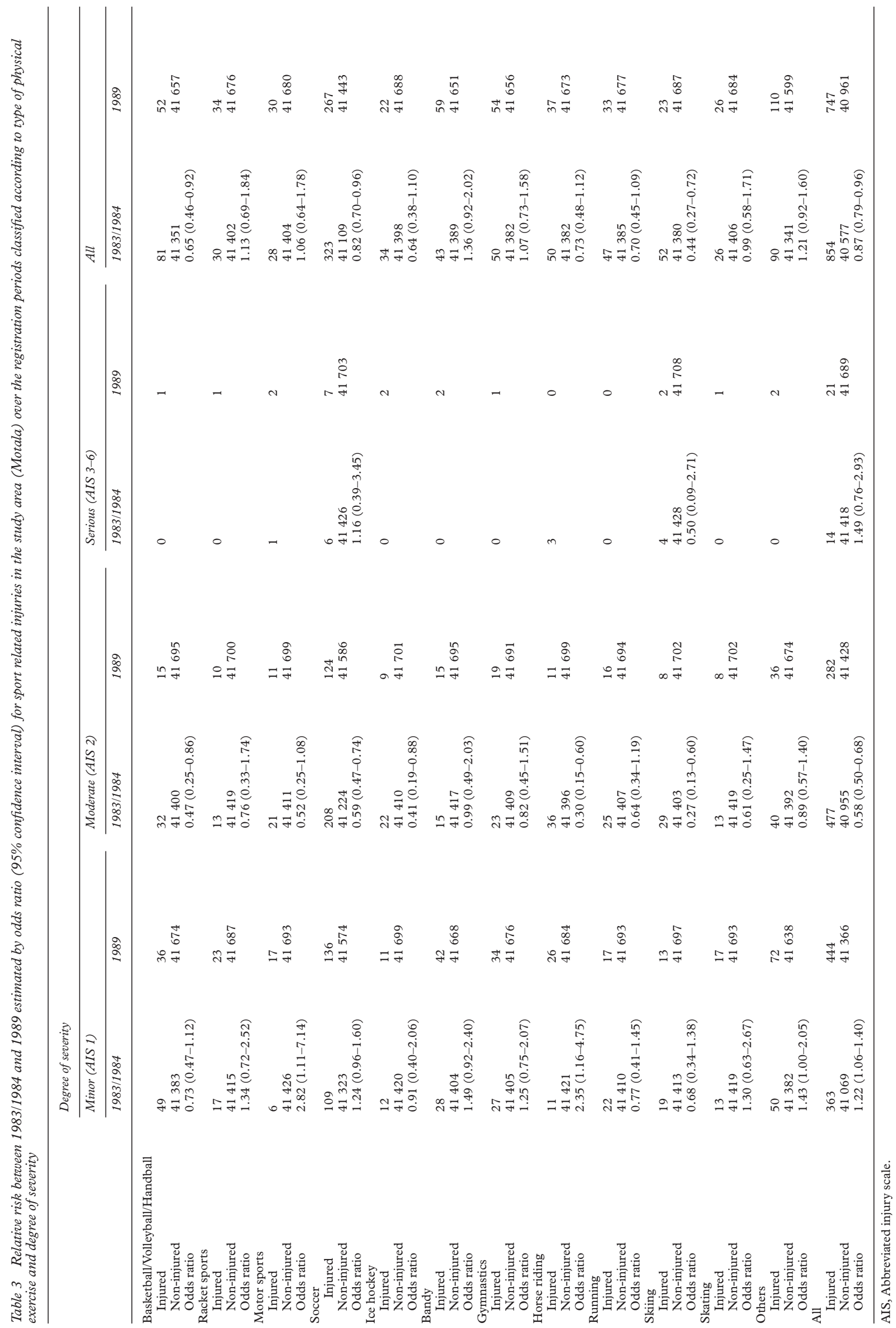

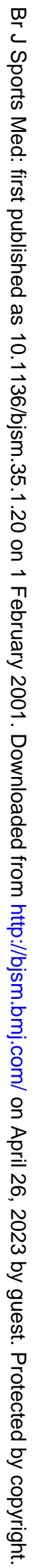




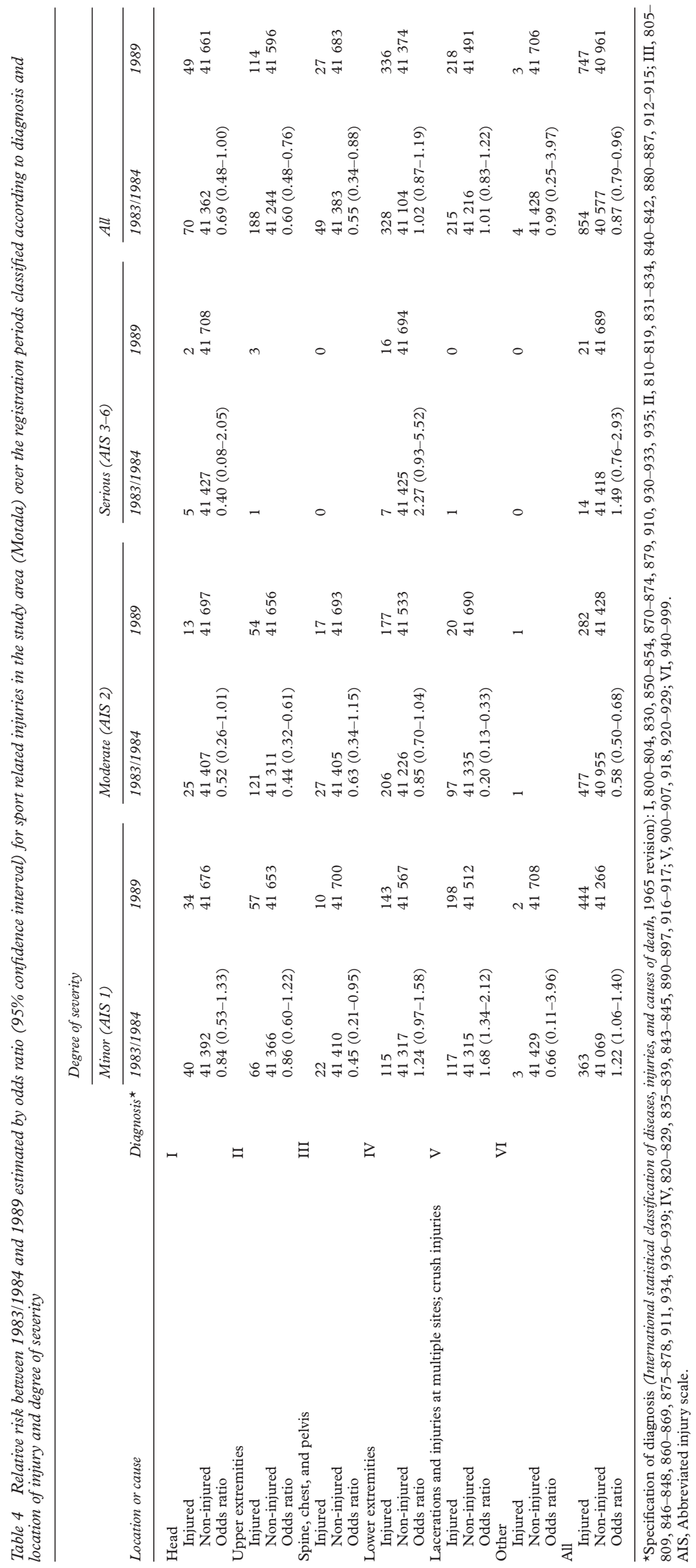

indications that the elimination of high risk situations by adhering to rules and norms for conduct in organised sports was successful. Rules that have been successful for preventing injuries have previously been reported for specific sports-for example, ice hockey-where compulsory use of the face mask by young players has virtually eliminated eye injuries. ${ }^{33}$ The greatest risk reduction observed in this study was for injuries to the upper extremities. A sports related injury to the upper extremities is typically caused by a collision or fall, events that are disadvantageous in most sports. Risk reduction can therefore be a consequence of the influence of the fair play programme on these specific, and for the nature of the physical exercise, unfavourable events. This observation is in accordance with previous studies, ${ }^{34}$ which have suggested that rules discouraging play that may result in collisions or falls can be recommended in programmes to prevent sports related injury without deviating from the spirit of the sport. Avoidance of high risk situations by enforcing rules does not have to be restricted to team sports. An example from an individual sport is the supervision rule for young and novice horse riders, which was associated with a decrease in relative risk of riding injuries to the upper extremities to one quarter.

The decrease in moderate soccer injuries was a major contribution to the total decline in injury rate. This decrease is probably a result of several combined factors. At a population level, the risk of sustaining a soccer injury is highest among children and teenagers. ${ }^{14}$ Even though injuries to the lower extremities are the most common in adult soccer ${ }^{35}$ in this study the injuries to the upper extremities decreased the most. One explanation is that the nature of soccer injuries differs between youths and adults. Compared with adults, children more seldom sustain knee and groin injuries, whereas injuries to the upper extremities are less common in adults. The decrease in injuries to the upper extremity can be explained by the fact that the rules for fair play in school and youth soccer have had a rapid effect. Although the physical preparation and warm up programmes reduced the injuries to the lower extremities in adult soccer, the effect was slower and spread beyond the time frame of this study. To be able to optimally adjust prevention of soccer injuries to different age groups, further longitudinal community level investigations are still required.

The lack of proper definitions is a hindrance to the study of sports related injuries. The fact that this study primarily had a public health, and not a sport competitor, focus is shown in the choice of scale for classification of injury severity. The AIS is validated with regard to clinical parameters and not measurements of injury severity usually used for sports - that 
is, the period of inability to perform physical exercise. $^{36}$ The scale is nevertheless well established for emergency room use and was, considering the study objectives, the obvious alternative for severity classification. There are few reasons to doubt that the AIS has sufficient validity for classification of acute sports injuries. However, an under-representation of overuse injuries is likely to have occurred.

The sociodemographic mix in the study and control areas are representative of general European populations, and the baseline sports related injury patterns correspond to previous studies. $^{37}{ }^{38}$ However, it has to be questioned how much of the decrease in morbidity can be attributed to the programme and to other factors. The study design was quasi-experimental, therefore external factors may have systematically influenced the results. Moreover, the individual specific risk exposure was not included in the analyses. As community level injury risk was the object of this study and participation in organised sports was controlled at the population level, the morbidity rate was considered to suffice. No evidence of change in exercise patterns or relevant environmental factors was observed during the study period. However, development of protective equipment for soccer players, for example, increased rapidly during the study period. The tendency toward a decrease in injury rates in the control area can thus be attributed to a general trend in prevention of sports related injury during the time of the study. However, both the total decrease and the decrease in non-minor injuries in the study area was of an extent that cannot be explained by general trends or chance.

In conclusion, a prevention programme based on evidence based promotion of fair play, supervision of novices, and compulsory use of protective equipment was found to reduce the rate and severity of injuries related to physical exercise in a local community. The effect was most pronounced for moderate injuries (AIS 2) and in the prevalent team sports. No effect was observed in the older age groups and on severe injuries (AIS 3-6). Community based programmes for injury prevention during physical exercise can be effective but need to be adjusted to include all age groups and types of physical exercise.

This study was supported by grants from the Swedish Centre for Sports Research (CIF), the Swedish National Institute of Public Health, the Swedish MTO programme, and the Östergötland County Council.

1 Terris M. Approaches to an epidemiology of health. Am $\mathcal{F}$ Public Health 1975;65:1037-45.

2 O'Connor G, Hennekens CH, Willett WC, et al. Physical exercise and reduced risk of nonfatal myocardial infarction. Am $\mathcal{F}$ Epidemiol 1995;142:1147-56.

3 Wannamethee SG, Shaper AG, Walker M. Changes in physical activity, mortality, and incidence of coronary heart disease in older men. Lancet 1998;351:1603-8.

4 Lissner L, Bengtsson C, Björkelund C, et al. Physical activity levels and changes in longevity. A prospective study of ity levels and changes in longevity. A prospective

5 Kujala UM, Kaprio J, Sarna S, et al. Relationship of leisuretime physical activity and mortality. The Finnish twin time physical activity and mort
6 Kelley GA. Aerobic exercise and bone density at the hip in postmenopausual women. Prev Med 1998;27:798-807.

7 Walther SD, Sutton JR, McIntosh JM, et al. The aetiology of sports injuries. Sports Med 1985;2:47-58.

8 De Loés M, Goldie J. Incidence rate of injuries during sport activity and physical exercise in a rural Swedish municipality: incidence rates in 17 sports. Int 7 Sports Med 1988;9:461-7.

9 Lindqvist K. Epidemiology of accidents in a Swedish municipality. Accid Anal Prev 1989;21:33-43.

10 Peterson L, Renström O. Injuries in sport. Gothenburg: Tiden Publishing Co, 1983.

11 Gerberich S. Sports injuries: implications for prevention. Public Health Rep 1985;100:570-1.

12 Schelp L. Epidemiology as a basis for evaluation of a community intervention program on accidents. Thesis. Karolinska Institutervention program on accidents.

13 Lindqvist K, Timpka T, Schelp L. Ten years of experiences froma participatory community-based injury prevention program in Motala, Sweden. Public Health 1996;110:33946.

14 Lindqvist $\mathrm{K}$, Timpka T, Bjurulf P. Injuries during leisure physical activity in a Swedish municipality. Scand f Soc Med 1996;24:282-92.

15 Lindqvist $\mathrm{K}$, Brodin $\mathrm{H}$. One-year economic consequences of accidents in a Swedish municipality. Accid Anal Prev 1996;28:209-19.

16 Vaz E. The professionalization of young hockey players. Lincoln, NE: Univerisity of Nebraska Press, 1982.

17 Ekstrand J, Gillquist J. Soccer injuries and their mechanisms: a prospective study. Med Sci Sports Exerc 1983;15:267-70.

18 Cook TD, Campell DT. Quasi-experimentation. Boston: Houghton Mifflin, 1979.

19 Swedish National Board of Health and Welfare. Classification of diseases 1968. Systematic list (International statistical classification of diseases, injuries, and causes of death, 1965 revision, adapted for indexing hospital records and morbidity statistics). (In Swedish.) Stockholm: Swedish National Board of Health and Welfare, 1982.

20 Petrucelli E, States JD, Hames LN. The Abbreviated Injury Scale: evolution, usage, and future adaptability. Accid Anal Prev 1981;13:29-35.

21 Baker SP, O’Neill B, Haddon W, et al. The Injury Severity Score: a method for describing patients with multiple injuries and evaluating emergency care. $\mathcal{f}$ Trauma 1974;14: $187-96$

22 Schelp L, Svanström L. A model for registration and mapping of accident cases in health care. Scand $\mathcal{F}$ Prim Health Care 1987;5:91-9.

23 Carley M. Social measurement and social indicators: issues of policy and theory. London: George, Allen \& Unwin, 1981.

24 Rothman J. Planning and organizing for social change: action principles from social research. New York: Columbia University Press, 1974

25 Turtz A, Crost M. Sport-related injuries in children. Am 7 Sports Med 1986;4:294-9.

26 Miettinen OS. Estimability and estimation in case-referent studies. Am f Epidemiol 1976;103:226-35.

27 Armitage P, Berry G. Statistical methods in medical research. Oxford: Blackwell Science Ltd, 1994.

28 Fletcher GF, Balady G, Blair SN, et al. Statement on exercise: benefits and recommendations for physical activity programs for all Americans. Circulation 1996;94:857-92.

29 NIH Consensus Conference. Physical activity and cardiovascular health. NIH consensus development panel on physical activity and cardiovascular health. $\mathcal{F} A M A$ 1996; 276:241-6.

30 van Mechelen W, Hlobil H, Kemper HC. Incidence, severity, aetiology and prevention of sports injuries. A review of concepts. Sports Med 1992;14:82-99.

31 Jorgensen U. Epidemiology of injuries in typical Scandinavian team sports. Br f Sports Med 1984;2:59-63.

32 Avery JG, Harper P, Ackroyd S. Do we pay dearly for our sport and leisure activities? Public Health 1990;104:417-23.

33 Biasca N, Simmen HP, Trentz O. Review of typical ice hockey injuries. Unfallschirurg 1995;98:283-5.

34 Roberts WO, Brust JD, Leonard B, et al. Fair-play rules and injury reduction in ice hockey. Arch Pediatr Adolesc Med 1996;150:140-5.

35 Ekstrand J. Soccer injuries and their prevention. Linköping University medical dissertations no 130. Linköping, Sweden: Linköping University, 1982 .

36 Watson AWS. Sports injuries: incidence, causes, prevention. Physical Therapy Reviews 1997;2:135-51.

37 De Loés M. Risk exposure and incidence rates of acute injuries from sports and physical exercise in a total population. Thesis. Department of Social Medicine, Karolinska Institute, and the Department of Orthopedic Surgery, Karolinska Hospital, Sundbyberg and Stockholm, Sweden, 1989.

38 Sahlin Y. Sports accidents in childhood. Br f Sports Med 1990;24:40-4. 


\section{Take home message}

In these days when physical exercise is promoted in public health campaigns, it is of concern that the effectiveness of broad sports injury prevention is lacking. The WHO safety community programme reduced the total incidence of sports related injuries by $14 \%$ in a local community, and the non-minor injury rate was reduced to almost half. Evidence based programmes can prevent severe sports related injuries in a community and should be used in parallel with promotion of physical exercise.

\section{British Association of Sport and Exercise Medicine in association with the National Sports Medicine Institute}

\section{Education programme 2001}

Injury management and medicine: head, neck and upper limb

Lilleshall Hall National Sports Centre, Shropshire

Diploma preparation course

11-16 February

Exact date and location to be confirmed

General sports medicine

Lilleshall Hall National Sports Centre, Shropshire

Current concepts

Topic, date, cost, and location to be confirmed

Injury management and medicine: thorax, groin, pelvis and hip Lilleshall Hall National Sports Centre

General sports medicine

Lilleshall Hall National Sports Centre

Practical sport and medicine meeting

March

22-27 April

Club La Santa, Lanzarote

Families and non-delegates welcome; booking deadline 31 July

Diploma preparation course

October

Exact date and location to be confirmed

1 May

8-13 July

23-28 September

BASEM Congress

Oct/Nov

Date, cost, and location to be confirmed

Injury Management and Medicine: lower limb

18-23 November

Lilleshall Hall National Sports Centre

\section{Current Concepts}

2 December

Topic, date, and location to be confirmed

For further details of these courses please contact Mr Barry Hill, The National Sports Medicine Institute, c/o Medical College of St Bartholomew's Hospital, Charterhouse Square, London EC1M 6BQ.

Tel: 02072510583 (ext 237); fax: 0207251 0774; email: barry.hill@nsmi.org.uk Web site: www.nsmi.org.uk 